\title{
Gerenciamento de resíduos da construção civil em um empreendimento de médio porte em Varginha, Minas Gerais, Brasil
}

\section{Fernando Caio Elias da Silva ${ }^{1}$, Sebastião Wellington Barbosa $^{1}$, Rosângela Francisca de Paula Vitor Marques ${ }^{2}, *$, Alisson Souza de Oliveira ${ }^{2}$ e Eliana Alcantra ${ }^{2}$}

\author{
${ }^{1}$ Universidade Vale do Rio Verde de Três Corações. Curso de Graduação em \\ Engenharia Ambiental e Sanitária. Av. Castelo Branco, 82. Chácara das Rosas. Três \\ Corações-MG, Brasil (CEP 37410-000). \\ ${ }^{2}$ Universidade Vale do Rio Verde de Três Corações. Av. Castelo Branco, 82. Chácara \\ das Rosas. Três Corações-MG, Brasil (CEP 37410-000). *E-mail: \\ rosangela.marques@unincor.edu.br.
}

Resumo. Empresas de construção civil geram grandes quantidades de resíduos, que, por meio do gerenciamento, perdas podem ser minimizadas e reduzidas com a reutilização e reciclagem. Assim, objetivou-se diagnosticar os resíduos de construção civil de acordo com as fases da obra e avaliar o gerenciamento em um empreendimento em construção civil no Município de Varginha, Estado de Minas Gerais, Brasil. Para o diagnóstico do processo de gestão e gerenciamento dos resíduos de construção civil foram realizadas visitas in loco. A quantificação e a caracterização gravimétrica dos resíduos de construção civil foram realizadas por meio da pesagem e separação dos resíduos nas classes A, B, C e D, de março a setembro de 2020. Observou-se que os resíduos variam de acordo com a fase de construção da obra, sendo os resíduos de classe A predominante (93\%) no início, e classe B (65\%) no meio da obra e ao final com aumento para $75 \%$, demonstrando a intensificação de gesso. Conclui-se que fase de execução da obra possui influência direta na geração de diferentes tipos de resíduos. A quantidade de resíduos foi de $29.500 \mathrm{~kg}, 9.300 \mathrm{~kg}$ e $7.850 \mathrm{~kg}$ para os meses de março, abril e agosto respectivamente. No gerenciamento, observou-se que os resíduos de classe B (gesso) não são destinados conforme a legislação. Assim sugere-se para melhoria do gerenciamento, a educação ambiental para os profissionais envolvidos no canteiro de obra, criação de acondicionamento temporário por classes de resíduos, venda dos resíduos de classe $\mathrm{B}$ a empresas de reciclagem e busca de parcerias para o reaproveitamento e a reinserção do material na cadeia produtiva.

Palavras-chave: Diagnóstico de resíduos de construção civil; Fase da construção; Política Nacional de Resíduos Sólidos.
Recebido

$27 / 01 / 2021$

Aceito

$27 / 08 / 2021$

Publicado

$31 / 08 / 2021$

Acesso aberto

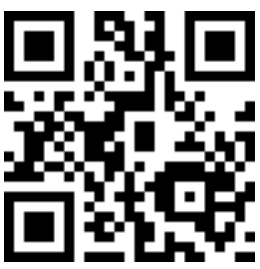

(D) 0000-0003-0185-4502 Fernando Caio Elias da Silva

(1) 0000-0001-9311-6034 Sebastião Wellington Barbosa

(1) 0000-0001-6646-0809 Rosângela Francisca de Paula Vitor Marques 
Abstract. Civil construction waste management in a mediumsized enterprise in Varginha, Minas Gerais, Brazil. Civil construction companies generate large amounts of waste, which can be minimized and reduced through reuse and recycling through management. Thus, the objective was to diagnose civil construction waste according to the construction phases and management assessment in a civil construction project in the Municipality of Varginha, State of Minas Gerais, Brazil. In order to diagnose the civil construction waste management and management process, on-site visits were made. The quantification and gravimetric characterization of civil construction waste was carried out by weighing and separating the waste in classes A, B, C and D, from March to September 2020. It was observed that the waste separated according to the construction of the work, with class A residues predominant (93\%) at the beginning, and class B $(65 \%)$ in the middle of the work and at the end with an increase to $75 \%$, demonstrating the intensification of plaster. It is concluded that the execution phase of the work has direct in the generation of different types of waste. The amount of waste was $29,500 \mathrm{~kg}, 9,300 \mathrm{~kg}$ and 7,850 kg for the months of March, April and August, respectively. In management, it was observed that class B waste (plaster) is not applied according to the legislation. Thus, it is essential to improve management, environmental education for professionals involved in the construction site, creation of temporary packaging for waste classes, sale of class B waste to recycling companies and search for partnerships for reuse and reinsertion of the material in the production chain.

Keywords: Diagnosis of civil construction waste; Construction phase; National Solid Waste Policy.
D) 0000-0001-7885-9542

Alisson Souza de

Oliveira

(ㄱ) 0000-0001-9292-3256

Eliana Alcantra

\section{Introdução}

A indústria da construção civil possui grande relevância para o desenvolvimento econômico do Brasil, agregando valor total das atividades, bem como na multiplicação de renda (Teixeira, 2010a). A construção civil é um dos setores que mais cresce no mundo, sendo reconhecida como uma importante atividade para o desenvolvimento econômico e social (Halmeman et al., 2009). Para Rabechini Jr. e Carvalho (2007) o setor da construção, desempenha papel estratégico no processo de desenvolvimento econômico do Brasil, sendo responsável pela geração de empregos diretos e indiretos dinamizando diversas cadeias produtivas pelo seu elevado efeito multiplicador e baixo coeficiente de importação. De acordo com o Instituto Brasileiro de Geografia e Estatística (IBGE, 2011), no ano de 2010 o setor da construção civil foi responsável por um crescimento de 11,6\% em seu PIB setorial, o melhor resultado dos últimos 24 anos, e pela geração de mais de 329 mil vagas formais no mercado de trabalho. Em 2017 O setor participou com 4,8\% do PIB nacional (IBGE, 2018). Contudo, o setor é uma grande fonte geradora de resíduos em seus processos produtivos, causando impactos ao meio ambiente.

A geração de resíduos é característica do meio antrópico uma vez que sua geração está diretamente ligado a suas atividades e meios de produção, afetando diretamente na quantidade e na diversidade de resíduos gerados (Hess, 2002). Tornando-se fonte de contaminação para o solo, água ou o ar e contribuindo na proliferação de vetores. 
Segundo a Resolução CONAMA no 307/2002 (Brasil, 2002), resíduos da construção civil são caracterizados como todos os materiais provenientes de construções, reformas, reparos e demolições de obras de construção civil, e os resultantes da preparação e da escavação de terrenos citando como exemplo tijolos, blocos cerâmicos, concreto, solos, rochas, metais, resinas, colas, tintas, madeiras e compensados, forros, argamassa, gesso, telhas, pavimento asfáltico, vidros, plásticos, tubulações, fiação elétrica dentre outros. Muitos desses materiais poderiam ser reaproveitados, reciclados ou até mesmos reutilizados. Nesse sentido, a Lei $\mathrm{n}^{0}$ 12.305/2010, que instituiu a Política Nacional de Resíduos Sólidos (PNRS), prevê o Plano de Gerenciamento de Resíduos Sólidos, sendo necessário também para obras de construção civil (Brasil, 2010). Este plano tem por objetivo realizar o gerenciamento de tais resíduos, minimizando, reduzindo gastos com seus tratamentos e disposição final, como base da hierarquia da geração de resíduos, remetendo a benefícios às empresas de construção civil, com a mudança de paradigmas, ou seja, o que anteriormente era visto como despesas no processo produtivo passa a ter valor agregando e trazendo receitas para os empreendimentos.

0 resíduo da construção civil é composto por materiais classificados como inerte, passível de reaproveitamento possibilitando inúmeros benefícios, como receita econômica, resultado da venda dos materiais. As economias correspondentes à redução no custo de transferência e disposição final desses materiais e benefícios sociais, principalmente, na geração de empregos diretos e indiretos (CEMPRE, 2000).

Segundo a ABNT NBR 10004:2004 (ABNT, 2004), a classificação de resíduos sólidos envolve a identificação do processo ou atividade que lhes deu origem, de seus constituintes e características, e a comparação destes constituintes com listagens de resíduos e substâncias cujo impacto à saúde e ao meio ambiente é conhecido. Para classificação faz-se necessário a segregação dos resíduos na fonte geradora e a identificação de origem, onde a descrição de matérias-primas, de insumos e do processo no qual o resíduo foi gerado devem ser explicitados. A identificação dos constituintes a serem avaliados na caracterização do resíduo deve ser estabelecida de acordo com as matérias-primas, os insumos e o processo que lhe deu origem.

A norma ABNT NBR 10004/2004 ainda sugere a classificação em relação à periculosidade, sendo Classe I - resíduos perigosos e Classe II - resíduos não perigosos. Os resíduos classe I - podem ser classificados conforme sua inflamabilidade, corrosividade, reatividade, toxidade e patogenicidade resíduos. Os resíduos de classe II - são ainda subdivididos em outras duas classes: 1) Resíduos classe IIA - Não Inertes, os quais possuem propriedades, tais como biodegradabilidade, combustibilidade ou solubilidade em água; 2) Resíduos classe IIB - Inertes, que são quaisquer resíduos que, quando amostrados de uma forma representativa, segundo a norma ABNT NBR 10007:2004 (ABNT, 2004), e submetidos a um contato dinâmico e estático com água destilada ou deionizada, à temperatura ambiente.

Além da norma ABNT NBR 10004:2004 (ABNT, 2004), existem ainda resoluções, como a Resolução CONAMA no 307/2002 (Brasil, 2002) e a Resolução CONAMA no 431/2011 (Brasil, 2011), nas quais são utilizadas classificação e complementação dos resíduos de construção civil (Tabela 1).

Além dessa classificação dos resíduos, que possibilita um manejo mais adequado, bem como o auxílio para o seu emprego como material reciclado, tendo diversas aplicações na construção civil, esta resolução estabelece ainda que os mesmos não possam ser dispostos em aterros de resíduos sólidos domiciliares ou em bota-fora. (Azevedo et al., 2006).

Tabela 1. Classificação dos resíduos de construção civil conforme Resolução CONAMA nº 307/2002 e Resolução CONAMA no 431/2011. 


\begin{tabular}{|c|l|}
\hline Classes & Integrantes predominantes considerados na composição gravimétrica \\
\hline A & $\begin{array}{l}\text { Resíduos recicláveis, como agregados, tijolos, blocos, telhas, argamassa, concreto, areia e } \\
\text { pedra }\end{array}$ \\
\hline B & $\begin{array}{l}\text { Resíduos recicláveis para outras destinações, tais como plásticos, papel, papelão, metais, } \\
\text { vidros, madeiras e gesso }\end{array}$ \\
\hline C & $\begin{array}{l}\text { Resíduos para os quais não foram desenvolvidas tecnologias ou aplicações } \\
\text { economicamente viáveis que permitam sua reciclagem ou recuperação }\end{array}$ \\
\hline D & Resíduos perigosos como tintas, solventes, óleos e amianto (contaminados) \\
\hline
\end{tabular}

Fonte: Resolução CONAMA no 307/2002 (Brasil, 2002) e Resolução CONAMA nº 431/2011 (Brasil, 2011).

Para Zordan (1997) os resíduos de construção civil em sua maior fração e constituídos por material não mineral como por exemplo argamassa, areia, cerâmicas, concretos, madeira, metais, papéis, plásticos, pedras, tijolos, tintas, metais, matéria orgânica e etc.).

Para Teixeira (2010b), os problemas que envolvem a geração dos resíduos sólidos é uma questão mundial. No caso de resíduos de construção civil é diretamente proporcional ao crescimento e ao desenvolvimento econômico de uma sociedade. Outro fator marcante é que humanidade torna-se cada vez mais urbana e, a produção de resíduo cresce proporcionalmente à urbanização.

Segundo o Instituto de Pesquisa Econômica Aplicada (IPEA, 2012), os resíduos da construção civil compõem cerca de $50 \%$ a $70 \%$ dos resíduos sólidos urbanos. No Brasil, conforme o Sindicato da Indústria da Construção Civil do Estado de São Paulo (SINDUSCON/SP, 2012), no Município de São Paulo produz uma média diária de $17.240 \mathrm{t}$ de resíduos sólidos urbanos, $55 \%$ dos quais provenientes da construção civil; em Campinas, essa proporção chegou a $64 \%$ no mesmo ano, sendo a construção formal é responsável pela geração de apenas $30 \%$ dos resíduos da construção civil, e os geradores informais os responsáveis pela maior parcela dos resíduos gerados.

Segundo Motta e Fernandes (2003) o desperdício de materiais na construção civil no Brasil é elevado e os resíduos gerados, possuem uma considerável heterogeneidade em termos da sua composição e sua quantidade. Variando de $54 \%$ a $70 \%$ dos resíduos sólidos urbanos de cidades brasileiras, como as ocorre no Rio de Janeiro e Belo Horizonte, representando uma geração per capita entre 0,4 e 0,76 t.hab ${ }^{-1} \cdot$ ano $^{-1}$. Estimativas internacionais sobre a geração per capita de resíduos de construção civil variam entre 130

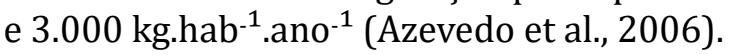

Segundo a Secretaria Nacional de Saneamento Ambiental - SNIS (Ministério das Cidades, 2010), com base nos dados de 2008, os municípios brasileiros coletam resíduos de construção civil diretamente ou por contratação de terceiros. Conforme demostrado por meio de amostra de pesquisa de 372 municípios brasileiros, a quantidade de coleta de resíduos da construção civil de origem publica foram de 7.192.372,71 t.ano $^{-1}$ e 7.365.566,51 t.ano ${ }^{-1}$ coletados de origem privada sendo valores expressivos quando comparados ao total de resíduo solido gerados.

Os impactos ocasionados pelos resíduos de construção civil dão-se principalmente devido a disposições irregulares, causando poluição visual, degradação do ambiente urbano por meio da contaminação do solo e da água, interferindo na drenagem urbana, proliferação de vetores. (John, 2000). Segundo Mendes (2004), grande parte dos municípios brasileiros, fazem uso de bota-fora clandestinos, margens de rios e córregos ou em terrenos baldios para deposição irregular dos resíduos da construção civil, ocasionando a proliferação de vetores de doenças, entupimento de galerias e bueiros, assoreamento de córregos e rios, contaminação de águas superficiais e poluição visual. 
Complementando, Angulo e John (2004) afirmam que a ineficiência de políticas públicas ou ausência das mesmas, influenciam a malha urbana a adoção de aterros clandestinos e o esgotamento de aterros inertes e/ou sanitários.

As empresas de construção civil geram grandes quantidades de resíduos, estas podem por meio do gerenciamento das etapas de construção, reduzir as perdas e minimizar a geração dos resíduos, que podem ser reutilizados e reciclados, deixando de ser um problema econômico, social e ambiental. A Resolução CONAMA no 307/2002 (Brasil, 2002) determina que os grandes geradores sejam os responsáveis pelo gerenciamento de seus resíduos, proibição do envio a aterros sanitários e a adoção do princípio da prevenção de resíduos, obrigando as empresas geradoras e prefeituras a tomarem medidas para diminuição dos resíduos de construção civil gerados.

A Política Nacional de Resíduos Sólidos (Lei no 12.305/2010) visa a trazer soluções para gestão integrada dos resíduos sólidos, de forma a considerar as dimensões política, econômica, ambiental, cultural e social. As ações exercidas de gerenciamento possuem etapas de coleta, transporte, transbordo, tratamento e destinação final dos resíduos sólidos e disposição final dos rejeitos, considerando que a destinação e disposição são ambientalmente adequadas, de acordo com os planos municipais de gestão integrada e de gerenciamento de resíduos sólidos, exigidos na referida lei (Brasil, 2010).

Segundo Schalch e Córdoba, (2011), o PNRS de estratégia para a gestão e o gerenciamento integrado de resíduos sólidos, tem como propriedade no tratamento de resíduos com a análise do ciclo de vida e diminuir o volume de atividades de tal forma que haja muito poucos resíduos a serem tratados, sejam eles de forma física, química e/ou biologicamente, até a inexistência da disposição final como mostra na Figura 1 a situação atual e ideal, conforme o PNRS, de estratégia para a gestão e o gerenciamento integrado de resíduos sólidos

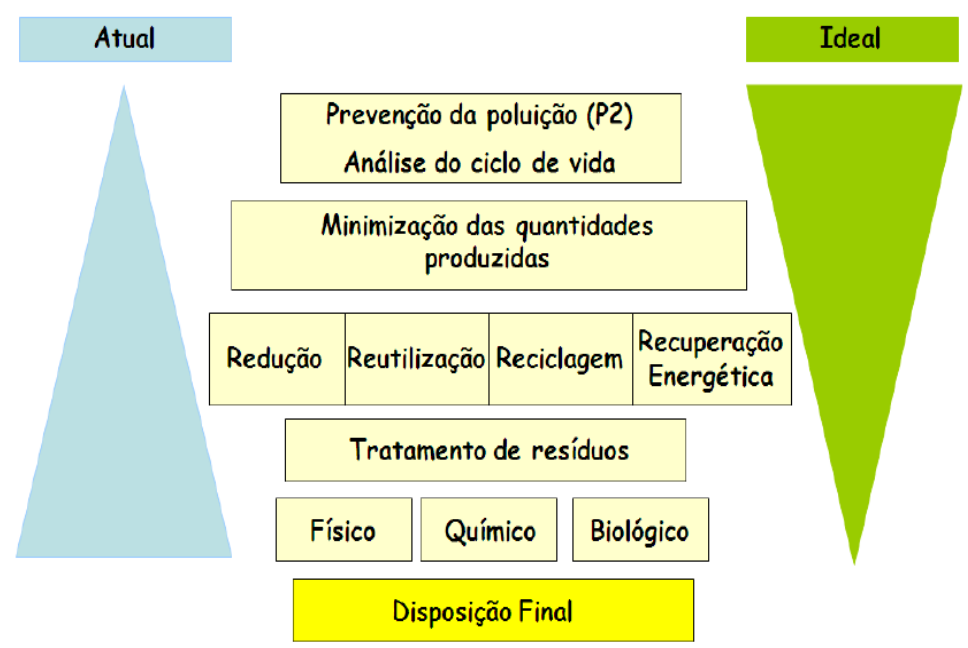

Figura 1. Estratégias para a gestão e o gerenciamento integrado dos resíduos sólidos. Fonte: Schalch e Córdoba (2011).

A Resolução CONAMA no 307/2002 (Brasil, 2002) estabelece diretrizes, critérios e procedimentos para o gerenciamento dos resíduos de construção civil, definindo os aspectos necessários para minimizar os impactos ambientais. Considerando que seus os geradores de resíduo de construção civil, são responsáveis pelo mesmo, impondo as empresas do setor e aos municípios, implementar ferramentais de gestão em seus 
processos garantindo a destinação ambientalmente correta por meio de qualificação, documentação de procedimentos de triagem, acondicionamento e disposição final dos resíduos gerados dispostos pela implementação do Projeto de Gerenciamento de Resíduos da Construção Civil (PGRCC) para os geradores e para os municípios institui a elaboração do plano integrado de gerenciamento de resíduos da construção civil. Outro aspecto abordado pela resolução é a redução, a reutilização, a reciclagem de modo a diminuir a quantidade de resíduos gerados.

A Resolução CONAMA no 448/2012 (Brasil, 2012),define o gerenciamento e gestão dos resíduos da construção civil como:

[...] conjunto de ações exercidas, direta ou indiretamente, nas etapas de coleta, transporte, transbordo, tratamento e destinação final ambientalmente adequada dos rejeitos, de acordo com plano municipal de gestão integrada de resíduos sólidos ou com plano de gerenciamento de resíduos sólidos, exigidos na forma da Lei no 12.305, de 2 de agosto de 2010 (Brasil, 2012).

Diante da legislação apresentada, é possível definir alguns procedimentos, ferramentas e técnicas, por meio de ações voltadas para determinação de um modelo de gestão (Figura 2).

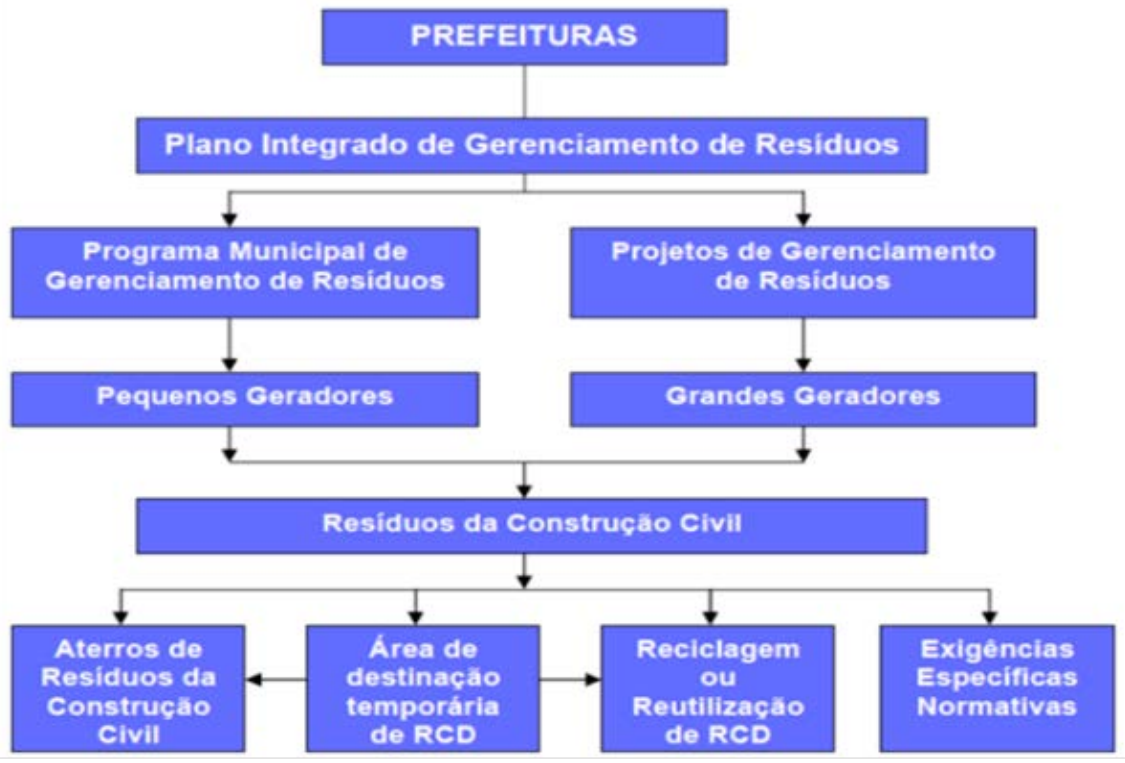

Figura 2. Fluxograma da gestão de resíduos de acordo com a Resolução CONAMA no 307/2002. Fonte: Carneiro (2005).

Assim, neste trabalho objetivou-se realizar o diagnóstico dos resíduos de construção civil gerados, avaliar o gerenciamento destes em um empreendimento em construção situado no Município de Varginha, Estado de Minas Gerais, bem como o a proposição de medidas ambientalmente adequadas a fim de minimizar, reduzir a geração de resíduos.

\section{Material e métodos}


O método adotado nesse trabalho foi à pesquisa quantitativa, que busca através de cálculos e atribuições possíveis de mensuração, entendendo de forma lógica enfatizar o raciocínio para dedução e interpretação dos resultados. A pesquisa qualitativa busca enfatizar todos os aspectos dinâmicos, de forma conjunta e individual da experiência da sociedade.

No primeiro momento, a pesquisa consistiu em levantamento bibliográfico, visando com isso o entendimento sobre a problemática apresentada, a legislação vigente buscando identificar as aplicações adotadas para as destinações finais ambientalmente adequadas dadas para os resíduos da construção civil.

\section{Caracterização do empreendimento}

O empreendimento estudado em relação ao gerenciamento dos resíduos de construção civil é uma obra de construção civil, construída com destinação comercial com uma área de 1.202,32 $\mathrm{m}^{2}$ divididos em dois pavimentos. Tendo início em 08/05/2019, onde foram realizados a sondagem do solo, terraplanagem e infraestrutura até final do ano de 2019. Em 2020, iniciou-se a fase de supraestrutura, ou seja, a fase de vedação, parede vergas e contra vergas, cobertura, revestimento, cerâmica, esquadrias, instalações hidrossanitárias, instalação elétrica e pintura. A obra está sendo executada por uma empresa especializada (construtora) e está em fase de acabamento tendo previsão de entrega da obra até o mês de dezembro de 2020.

\section{Levantamento e processamento dos dados}

Foi realizado o levantamento dos resíduos gerados por meio de vistas técnicas em empreendimento comercial em fase de construção situado no Município de Varginha, Estado de Minas Gerais, objetivando realizar um diagnóstico do processo de gestão e gerenciamento dos resíduos de construção civil (geração, acondicionamento, transporte, destinação e disposição e disposição final), que é atualmente empregado pela construtora responsável pelo empreendimento.

Para a quantificação e caracterização gravimétrica dos resíduos gerados, foi realizado um monitoramento no período de março a setembro 2020. Os resíduos foram armazenados em caçambas de $7 \mathrm{~m}^{3}$ e, posteriormente separados nas classes A, B, C e D e tipologias conforme classificação da Resolução CONAMA no 307/2002 (Brasil, 2002) e da Resolução CONAMA no 431/2011 (Brasil, 2011) e posteriormente pesados. (1):

Para a determinação da composição gravimétrica, utilizou-se a seguinte fórmula

$$
C(\%)=\frac{\text { Peso da fração do material }(\mathrm{kg})}{\text { Peso total da amostra }(\mathrm{kg})} X 100
$$

Em que:

$\mathrm{C}(\%)=$ categoria em porcentagem.

Peso da fração do material= fração separadas nas classes A, B, C e D conforme Resolução CONAMA no 307/2002 (Brasil, 2002).

\section{Tratamento dos dados}

Os dados foram processados por meio de planilhas em Excel e plotagem de gráficos, expressos em porcentagem, com as quantidades de resíduos por tipologias e classes. Foi realizada também a descrição do processo de gerenciamento das diversas etapas. Posteriormente os dados foram discutidos conforme as diretrizes previstas na 
Política Nacional de Resíduos Sólidos (Lei no 12.305/2010) e comparados com valores da Resolução CONAMA no 307/2002 (Brasil, 2002), de acordo com o tipo de processo adotado e comparado com diversos estudos.

Para o gerenciamento dos resíduos gerados foi proposto possíveis melhorias em seus processos de gestão, para redução, minimização, e/ou reaproveitamento dos resíduos da construção civil, de acordo com levantamentos bibliográficos.

\section{Resultados e discussão}

\section{Geração de resíduos sólidos}

A Tabela 2 apresenta o peso total em quilogramas por classes de resíduos segundo a Resolução CONAMA no 307/2002 (Brasil, 2002).

Observou-se que o total de resíduos gerados no mês de março foi de $29.550 \mathrm{~kg}$ sendo o resíduo predominante de classe A. Nos meses de abril e agosto, a classe predominante foi a classe $B$, além da mudança de predominância de classe, observou-se ainda a redução dos resíduos de classe $\mathrm{A}$, sinalizando à mudança de fase de acabamento no empreendimento, podendo ser corroborado com as Figuras 3, 4 e 5.

Tabela 2. Peso total em quilogramas e subdivididos em classes de resíduos da construção civil (RCC).

\begin{tabular}{|l|c|c|c|c|c|}
\hline \multirow{2}{*}{ Mês de coleta } & \multirow{2}{*}{ Peso total (kg) } & \multicolumn{4}{|c|}{ Peso por classe de RCC (kg) } \\
\cline { 3 - 6 } & & A & B & C & D \\
\hline Março & 29.550 & 27.350 & 2.200 & 0 & 0 \\
\hline Abril & 9.300 & 3.300 & 6.000 & 0 & 0 \\
\hline Agosto & 7.850 & 1.750 & 6.100 & 0 & 0 \\
\hline
\end{tabular}

As Figuras 3, 4 e 5 apresentam a geração de resíduos sólidos na obra de construção civil nas diferentes épocas da construção, por meio da quantificação, composição gravimetria e classificação por tipologia adotando as variáveis da Resolução CONAMA no $307 / 2002$.

Observou-se a geração de resíduos nas classes A e B, sendo que foi possível a verificação das fazes de execução da obra por meio dos das classes de resíduos gerados.

Na Figura 3, observou-se que 93\% dos resíduos gerados são da classe A, ou seja, que representa os resíduos reutilizáveis ou recicláveis como agregados (tijolos, blocos, telhas, placas de revestimento etc.) representando. Ressalta-se que esses materiais são utilizados no canteiro de obra nas fases de alvenaria de vedação, caraterizados pela fase inicial da obra.

Valor similar foram encontrados por Bernardes et al. (2008) no Município de Passo Fundo, Estado do Rio Grande do Sul, onde foram avaliadas as quantidades e as características dos resíduos de construção e demolição, de acordo com a Resolução CONAMA no 307/2002 (Brasil, 2002) e com a ABNT NBR 10004:2004 (ABNT, 2004). Assim foram obtidas as cifras de $94,8 \%$ dos resíduos como sendo de classe A, 3,1\% de classe B e $2,1 \%$ de Classe $\mathrm{C}$, remetendo à importância de um plano de gerenciamento adequado, bem como o reaproveitamento ou a reciclagem dos resíduos. Entretanto, cabe ressaltar ainda que os estudos de Bernardes et al. (2008), não se levou em conta as fases de construção de empreendimentos, como o do presente estudo. 


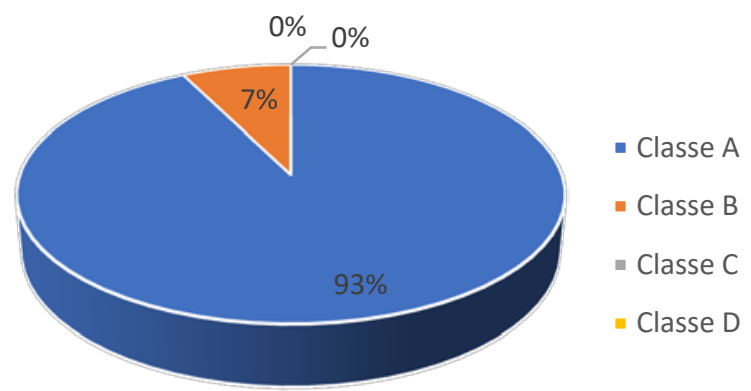

Figura 3. Porcentagem de resíduos de construção civil classificados nas classes A, B, C e D, conforme a Resolução CONAMA no 307/2002, no mês de março de 2020.

Na Figura 4, referente ao mês de abril, pode-se observar que ocorreu uma redução significativa dos resíduos da classe A se comparado com o mês de março (Figura 3), o que possivelmente dá-se devido à fase de execução da obra, tendo os resíduos da classe $\mathrm{A}$ alcançado 35\% de todo resíduo gerado e os da classe B, caracterizados por resíduos recicláveis para outras destinações, como plásticos, papel, papelão, metais, vidros, madeiras, embalagens vazias de tintas imobiliárias e gesso, aumentando de $7 \%$ no mês do março para $65 \%$ no mês de abril.

Tais alterações deram-se pelo avanço da obra que no mês de abril que entrou na fase do acabamento interno de parede, que utiliza revestimento de gesso.

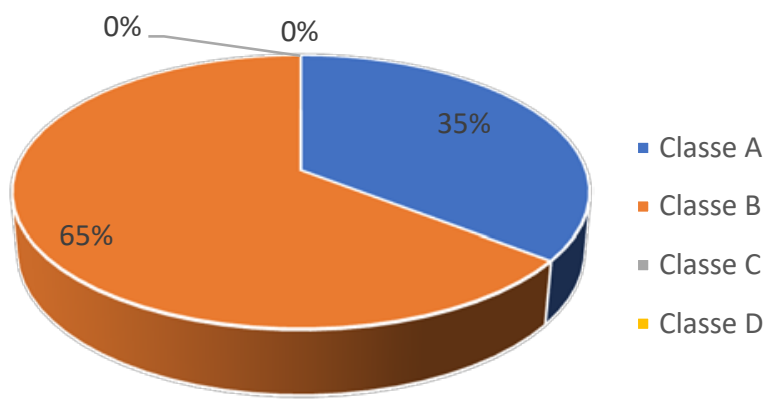

Figura 4. Porcentagem de resíduos de construção civil classificados nas classes A, B, C e D, conforme a Resolução CONAMA no 307/2002, no mês de abril de 2020.

Na Figura 5, referente à produção de resíduos no mês de agosto, demonstra que, do mesmo modo que no mês de abril, houve o predomínio de resíduos da classe $B$, com um incremento de $10 \%$, totalizando $75 \%$ dos resíduos no período, podendo observar a intensificação da utilização de gesso no revestimento interno, relacionado à fase de acabamento. Em estudos obtidos por Novaes e Morão (2008), estudando a geração de resíduos em obras verticais da capital cearense, foi relatado que a quantidade de resíduos da classe B soma apenas $10 \%$ dos resíduos gerados (Novaes e Mourão, 2008), divergindo 
dos resultados obtidos nesta pesquisa, que possivelmente pode ser atribuído a diferentes fases, ou diferentes processos de construção do canteiro de obras.

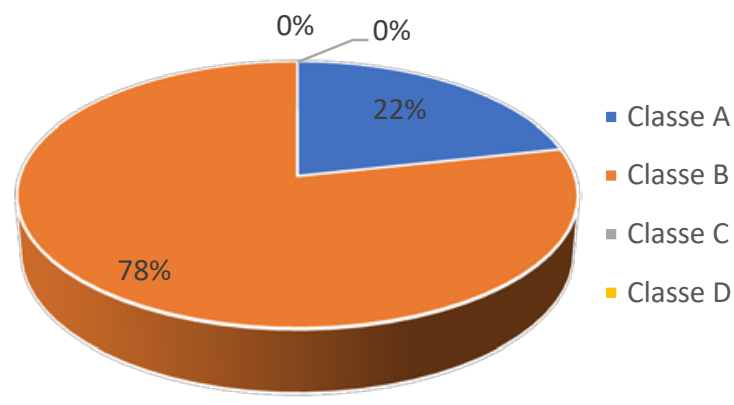

Figura 5. Porcentagem de resíduos de construção civil classificados nas classes A, B, C e D, conforme a Resolução CONAMA no 307/2002, no mês de agosto de 2020.

Outro dado importante a ser considerado são os resíduos da classe C e D, que não foram observados no presente estudo, sendo que para esses resíduos não foram desenvolvidas tecnologias ou aplicações economicamente viáveis que permitam a sua reciclagem ou recuperação. Esses resíduos, classificados como perigosos, ainda não foram utilizados na obra, sendo mais comuns na fase final de acabamento.

\section{Gerenciamento de resíduos da construção civil no canteiro de obra}

0 gerenciamento dos resíduos da construção civil do canteiro de obra em estudo é realizado por meio de uma empresa terceirizada, na qual são observadas as etapas de armazenamento, transporte e destinação final.

Assim, os resíduos gerados são acondicionados em caçambas estacionárias com capacidade de $6 \mathrm{~m}^{3}$.

Posteriormente, após o enchimento da caçamba estacionária, a mesma é recolhida pelo caminhão e transportada até a unidade da empresa terceirizada, responsável pela destinação final.

Quando os resíduos de construção civil depositados na caçamba chegam à empresa por meio do transporte de caminhão, faz-se a pesagem do caminhão cheio e caminhão vazio para a tara, por meio de uma balança de carga, objetivando a obtenção do peso.

A partir da pesagem, o caminhão é descarregado na área de triagem e segregação dos resíduos. Assim, os resíduos são separados da seguinte maneira, resíduos classe B (plásticos, papel, papelão, PVC, latão etc.) onde são acondicionados em caçambas estacionarias de 10 metros cúbicos e posteriormente comercializado para cooperativa local de reciclagem, sem a realização da prensagem.

Os resíduos de classe A (aglomerados de cerâmica e cimentícios) são separados entre si, e passados nos trituradores do tipo mandíbula e separados por meio de esteiras conforme sua granulometria. Do processamento dos cimentícios, são produzidos areia, brita 0 , brita 1 e rachão. Dos resíduos cerâmicos resultam em pedrisco, pedra 1, popularmente chamada "pedra rachão" ou "pedra maior", que são vendidos para usos não estruturais na cadeia produtiva da construção civil e uso em manutenção de estradas não pavimentadas do Município de Varginha. 


\section{Aspectos gerais}

Confrontando-se o gerenciamento dos resíduos da construção civil, realizado pela empresa terceirizada e com a Resolução CONAMA no 307/2002 (Brasil, 2002) pode-se verificar que, embora a Resolução CONAMA no 431/2011 (Brasil, 2011) classifique o gesso como resíduo classe $\mathrm{B}$, o mesmo não possui processo adequado de reaproveitamento na usina em estudo, sendo necessário seu descarte em área de disposição final regularizado pela prefeitura municipal.

A reciclagem do gesso pode ocorrer quando o material pode ser utilizado como fertilizante na agricultura, após a moagem, no qual atuará como corretivo da acidez do solo e melhoramento de suas características (Nogueira et al., 2016) ou pode também ser utilizado na indústria do cimento como um ingrediente que atua como retardante da cura do cimento (Seffrin et al., 2020) e, ainda, pode retornar a cadeia produtiva de construção quando submetido à calcinação após a moagem, transformando-o em gesso reciclado e apto para retornar ao início da cadeia produtiva (Cipriano da Silva et al., 2018).

Ressalta-se que o não reaproveitamento do gesso no empreendimento em questão, pode estar relacionado ao acondicionamento dos resíduos realizado no canteiro de obras, onde os resíduos de todas as classes são armazenados em uma única caçamba para todas as classes de resíduo, perdendo o seu valor agregado.

Assim, segundo o IBAM (2001), os critérios utilizados para o acondicionamento devem ser compatíveis com o tipo e quantidade de resíduos, com o objetivo de evitar acidentes, a proliferação de vetores, minimizar odores e o impacto visual negativo.

Outro aspecto que deve ser levado em conta é a falta de informação por parte dos profissionais (colaboradores e terceiros) trabalhadores no canteiro de obras, observado por meio das visitas in loco e/ou instrução quanto a geração, reaproveitamento e separação dos resíduos gerados no canteiro.

Cabe destacar que o objetivo do gerenciamento de resíduos da construção civil é realizar a gestão eficiente dos resíduos gerados nos canteiros de obras e definir as etapas de acondicionamento, transporte e tratamento e destinação final, conforme a Política Nacional de Resíduos Sólidos (Brasil, 2012) e pela Resolução CONAMA no 307/2002 (Brasil, 2002).

Sendo assim, sugere-se que a educação ambiental é de suma importância, para conscientização e capacitação dos profissionais envolvidos no canteiro de obras, bem como a criação de métodos de acondicionamento prévio dos resíduos mais adequados como por meio de baias "divisórias de madeira" ou recipientes plásticos rígidos para facilitar a identificação dos materiais e melhor aproveitamento dos mesmos. Por fim recomenda-se que a empresa "usina de reciclagem" anteriormente citada, buscasse por meio de parcerias ou outras empresas uma melhor destinação final dos resíduos de gesso o qual atualmente não tem o aproveitamento e a reinserção do material na cadeia produtiva.

\section{Conclusões}

A fase de execução da obra possui influência direta na geração de diferentes tipos de resíduos.

A quantidade de resíduos para o mês de março foi de $29.500 \mathrm{~kg}$, no mês de abril de $9.300 \mathrm{~kg}$ e agosto $7.850 \mathrm{~kg}$, sendo que os resíduos mais comuns no início da obra foram os da classe A (93\%) e ao avançar as etapas de execução os resíduos da classe B (65\%), aumentando para (75\%) ao final da obra, sendo pronunciado devido ao maior uso do material gesso. No atual gerenciamento de resíduo adotado esse tipo de material não possui destinação ambientalmente adequada.

0 gerenciamento de resíduos do empreendimento é composto pelas fases de armazenamento, transporte e destinação final, sendo que os resíduos de classe A e classe B 
possuem destinação final ambientalmente adequada e apresenta valor econômico, uma vez que é possível seu reaproveitamento e comercialização.

Os resíduos de gesso, mesmo sendo classificados como da classe B, não possui viabilidade técnica e econômica no Município de Varginha para sua reciclarem e reaproveitamento. Assim sugere-se para melhoria do gerenciamento do empreendimento, a educação ambiental para todos os profissionais envolvidos no canteiro de obra, criação de método de acondicionamento temporário por classes de resíduos, como exemplo uso de divisórias ou baias, venda dos resíduos de classe $\mathrm{B}$ a empresas de reciclagem, bem como a busca de parcerias com outras empresas para uma melhor destinação do gesso e comercialização de resíduos da classe A.

\section{Conflito de interesses}

Os autores declaram não haver conflito de interesses.

\section{Referências}

ABNT - Associação Brasileira de Normas Técnicas. ABNT NBR 10004:2004 - Resíduos sólidos - Classificação. Rio de Janeiro: ABNT, 2004.

ABNT - Associação Brasileira de Normas Técnicas. ABNT NBR 10007:2004 Amostragem de resíduos sólidos. Rio de Janeiro: ABNT, 2004.

Angulo, S. C.; John, V. M. Variabilidade dos agregados graúdos de resíduos de construção e demolição reciclados. e-Mat - Revista de Ciência e Tecnologia de Materiais de Construção Civil, v. 1, n.1, p. 22-32, 2004.

Azevedo, G. O. D.; Kiperstok, A.; Moraes, L. R. S. Resíduos da construção civil em Salvador: os caminhos para uma gestão sustentável. Engenharia Sanitária e Ambiental, v. 11, p. 65-75, 2006. https://doi.org/10.1590/S1413-41522006000100009

Bernardes, A.; Thomé, A.; Prietto, P. D. M.; Abreu, Á. G. Quantificação e classificação dos resíduos da construção e demolição coletados no Município de Passo Fundo, RS. Ambiente Construído, v. 8, n. 3, p. 65-76, 2008.

Brasil. Lei no 12.305, de 2 de agosto de 2010. Institui a Política Nacional de Resíduos Sólidos; altera a Lei no 9.605, de 12 de fevereiro de 1998; e dá outras providências. Disponível em: <http://www.planalto.gov.br/ccivil_03/_ato2007-2010/2010/lei/ 112305.htm>. Acesso em: 20 mar. 2020.

Brasil. Resolução CONAMA no 307, de 5 de julho de 2002. Dispõe sobre critérios e procedimentos para a gestão dos resíduos da construção civil. Disponível em: <http://www2.mma.gov.br/port/conama/legiabre.cfm?codlegi=307>. Acesso em: 20 mar. 2020.

Brasil. Resolução CONAMA no 431, de 24 de maio de 2011. Dispõe sobre nova classificação para o gesso. Disponível em: <http://www2.mma.gov.br/port/conama/ legiabre.cfm?codlegi=649>. Acesso em: 20 mar. 2020.

Brasil. Resolução CONAMA no 448, de 18 de janeiro de 2012. Altera o arts. $2^{\circ}, 4^{\circ}, 5^{\circ}, 6^{\circ}$, 8o, 9o , 10, 11 da Resolução no 307, de 5 de julho de 2002, do Conselho Nacional do Meio Ambiente-CONAMA. Disponível em: <http://www2.mma.gov.br/port/conama/ legiabre.cfm?codlegi=672>. Acesso em: 20 mar. 2020.

Carneiro, F. P. Diagnóstico e ações da atual situação dos resíduos de construção e demolição na Cidade do Recife. João Pessoa: Universidade Federal da Paraíba, 2005. (Dissertação mestrado). 
CEMPRE - Compromisso Empresarial para Reciclagem. Lixo municipal: manual de gerenciamento integrado. São Paulo: CEMPRE, 2000.

Cipriano da Silva, D. G.; Santana, C. V.; Póvoas, Y. V. Production of components with plaster residue and sodium citrate:physical, mechanical, rheological analysis. Ambiente

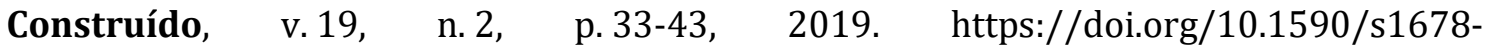
86212019000200304

Halmeman, M. C. R.; Souza, P. C; Casarin, A. N. Caracterização dos resíduos de construção e demolição na unidade de recebimento de resíduos sólidos no Município de Campo Mourão-PR. Revista Tecnológica, ed. esp., p. 203-209, 2009. https://doi.org/10.4025/ revtecnol.v0i0.8821

Hess, S. Educação ambiental: nós no mundo. 2. ed. Campo Grande: Ed. UFMS, 2002.

IBAM - Instituto Brasileiro de Administração Municipal. Manual de gerenciamento integrado de resíduos sólidos. 1. ed. Rio de Janeiro: IBAM, 2001.

IBGE - Instituto Brasileiro de Geografia e Estatística. Anuários estatísticos do Brasil. 2018. Disponível em: <http://ibge.gov.br/home/geografia/ambientais/ids/ids.pdf>. Acesso em: 20 mar. 2020.

IBGE- Instituto Brasileiro de Geografia e Estatística. Censo demográfico, 2010. Rio de Janeiro: IBGE, 2011.

IBGE- Instituto Brasileiro de Geografia e Estatística. Perfil dos municípios brasileiros 2011. Disponível em: <http://www.ibge.gov.br>. Acesso em: 10 mar. 2020.

IPEA - Instituto de Pesquisa Econômica Aplicada. Diagnóstico dos resíduos sólidos da construção civil. Brasília: IPEA, 2012. (Relatório de pesquisa). Disponível em: <http://www.ipea.gov.br/agencia/images/stories/PDFs/relatoriopesquisa/120911_relat o rio_construcao_civil.pdf $>$. Acesso em: 27 mar. 2020.

John, V. M. Reciclagem de resíduos na construção civil: contribuição para metodologia de pesquisa e desenvolvimento. São Paulo: Escola Politécnica da Universidade de São Paulo, 2000. (Tese de livre docência).

Mendes, T. A.; Rezende, L. R.; Oliveira, J. C.; Guimarães, R. C.; Camapum de Carvalho, J.; Veiga, R. Parâmetros de uma pista experimental executada com entulho reciclado. Anais da 35 Reunião Anual de Pavimentação, Rio de Janeiro, 2004.

Ministério das Cidades. Sistema Nacional de Informações sobre Saneamento (SNIS): diagnóstico do manejo de resíduos sólidos urbanos 2008. Brasília: Ministério das Cidades, 2010 .

Motta, L. M. G.; Fernandes, C. Utilização de resíduo sólido da construção civil em pavimentação urbana. Anais da 12a Reunião de Pavimentação Urbana, ABPv, Aracaju, 2003.

Novaes, M. V.; Mourão, C. A. M. A. Manual de gestão ambiental de resíduos sólidos na construção civil. 1. ed. Fortaleza: COOPERCON-CE, 2008.

Nogueira, K. B.; Roque, C. G.; Borges, M. C. R. Z.; Troleis, M. J. B.; Barreto, R. F.; Oliveira, M. P. Atributos físicos do solo e matéria orgânica sob dois manejos e efeito residual da aplicação de calcário e gesso agrícola. Revista de la Facultad de Agronomía, v. 115, n. 1, p. 45-54, 2016.

Rabechini Jr., R.; Carvalho, M. M. (Orgs.). Gerenciamento de projeto na prática: casos brasileiros. 1. ed. São Paulo: Atlas, 2007. 
Schalch, V.; Córdoba, R. E. Estratégia para gestão de resíduos sólidos. São Carlos: Escola de Engenharia de São Carlos, Universidade de São Paulo, 2011. (Material didático elaborado para a disciplina de Gestão Ambiental).

Seffrin, M. C. R. T.; Souza, J. V. T. A.; Oliveira, M. R.; Gonçalves, E. P. Reciclagem de gesso de demolição e influência da adição de retardadores de cura nas propriedades mecânicas. Revista Tecnologia e Tendências, v. 11, n. 1, p. 53-71, 2020. https://doi.org/10.25112/ rtt.v11i1.2295

SINDUSCON/SP - Sindicato da Indústria da Construção Civil do Estado de São Paulo. Resíduos de construção civil e o Estado de São Paulo. São Paulo: SINDUSCON/SP, 2012.

Teixeira, C. A. G. Jogando limpo: estudo das destinações finais dos resíduos finais dos resíduos sólidos da construção civil no contexto urbano de Montes Claros. Montes Claros: Universidade Estadual de Montes Claros, 2010a. (Dissertação de mestrado).

Teixeira, L. P. Desempenho da construção brasileira. Belo Horizonte: UFMG, 2010b.

Zordan, S. E. A utilização do entulho como agregado, na confecção do concreto. Campinas: UNICAMP, 1997. (Dissertação de mestrado). 